\title{
The Relationship between Cord Blood and Heel Prick Filter Paper Thyroid Stimulating Hormone Levels in the Light of Perinatal Factors
}

\author{
Faten Ghanem, Rayan Itani, Amal Naous ${ }^{*}$, Bassem Abou Merhi, Mariam Rajab
}

MD, Pediatric Department, Makassed General Hospital, Beirut, Lebanon

DOI: $10.36347 /$ sjmcr.2020.v08i02.002

| Received: 20.12.2019 | Accepted: 27.12.2019 | Published: 08.02.2020

*Corresponding author: Amal Naous

\section{Abstract}

Original Research Article

Background: Congenital Hypothyroidism most common preventable cause of mental retardation with incidence of 1:2500 to 1:2800 live births. Early diagnoses is crucial, thus various screening programs were initiated. Neonatal screening programs include either cord blood TSH at birth or heel prick TSH at 24-48 hours of life. However these studies are influenced by multiple maternal and perinatal factors thus yielding false high positive results. Objectives: Our study objectives were to study the relationship between cord blood TSH taken at birth and heel prick filter paper TSH that is taken at 24-48 hours of life routinely for neonatal screening, and to compare the influence of perinatal factors on both levels. Methods: We carried out a cross-sectional study in the regular nursery at Makassed General Hospital (MGH). We included 252 live newborns delivered between November 2016 and February 2017 and between November 2018 and February 2019. Blood was drawn directly at birth from the maternal side of the umbilical cord for cord TSH and another sample was drawn at 24-48 hours of life from heel prick for neonatal screening TSH. The two samples were then compared in light of perinatal factors. Results: Cord blood TSH values were found to be normal limits in neonates, not affected significantly with any of the prenatal factors studied as for maternal age, mode of delivery, gender, birth weight, gestational age, birth order, pregnancy course, and maternal illness. None of the studied parameters had a significant effect on heel prick TSH. Cord blood TSH was of average $=6.8$ in comparison to heel prick TSH average $=5$ (P-value $<0.0001)$ but still within normal levels. Comparison between the Cord-Heel TSH differences was not significantly affected by any of the above parameters. Conclusion: Cord blood TSH has the advantage of being easy to collect, non-invasive, and has better compliance from the parents. This study showed that there is no influence of any prenatal stressful condition and mode of delivery on levels of cord blood which make it the best and safest technique to diagnose Congenital Hypothyroidism. On the other hand, heel prick TSH is more invasive, has less compliance for follow up, and overlaps with the physiologic peak that the TSH has postnatal.

Keywords: Cord Blood, Perinatal Factors, mental retardation.

Copyright @ 2020: This is an open-access article distributed under the terms of the Creative Commons Attribution license which permits unrestricted use, distribution, and reproduction in any medium for non-commercial use (NonCommercial, or CC-BY-NC) provided the original author and source are credited.

\section{INTRODUCTION}

Congenital hypothyroidism is one of the most common preventable causes of intellectual disability. There is an inverse relationship between age at clinical diagnosis and treatment initiation and intelligence quotient (IQ) later in life, so that the longer the condition goes undetected, the lower the IQ [1].

Thyroid hormone is important for normal development of the nervous system [2]. The critical period for the central nervous system to be dependent on thyroid hormone is known to extend from fetal life until at least the first two years after birth [3]. Congenital hypothyroidism $(\mathrm{CH})$ of any cause is difficult to be recognized in neonatal period because of normal gross appearance [4]. The delayed diagnosis made only on the basis of clinical findings may result in irreversible complications such as mental retardation and deafness [5, 6]. The difficulty in recognizing congenital hypothyroidism and the serious consequences of delayed therapy have led to the introduction of screening programs for hypothyroidism in newborns by measuring (thyroxine) $\left(\mathrm{T}_{4}\right)$ or thyroidstimulating hormone (TSH ) in spots of blood collected via heel stick during the first few days of life [7, 8]. Screening programs for $\mathrm{CH}$ were first established in North America in 1972 [9].

Prevalence of hypothyroidism worldwide has been estimated to be 1:1465, with $1: 1800$ cases in Lebanon. Efforts made to improve the screening programs have led to improved developmental outcomes in adults who had congenital hypothyroidism 
who are currently in their 20 s and 30 s. Today, there are new methods for early detection and management of these hypothyroid neonates thus providing a better prognosis for further life $[10,11]$.

Multiple screening methods are available for early detection of congenital hypothyroidism to provide treatment before two weeks of age.

It is important to screen all infants at birth taking into consideration the transient elevation of TSH level during the first 24-48 hours of life [12].

Testing of these infants is best done between two to four days of life, however if not applicable, testing should be done whenever possible before 7 days of life. Screening before discharge is always preferable to missing the diagnosis [12].

The problem faced today is the increasing number of false results due to levels taken between 2448 hours of life, with parents losing follow up after requesting repeat of these levels, thus hindering the proper diagnosis and treatment of these infants.

Thyroid hormones undergo rapid and dramatic changes in the immediate postnatal period. An acute release of TSH occurs within minutes after birth. Peak values of $60-80 \mathrm{uU} / \mathrm{Ml}$ are seen at $30-90 \mathrm{~min}$. Levels decrease to $<5 \mathrm{uU} / \mathrm{mL}$ by $3-5$ days [13]. The ideal time for screening is between days 2 and 6 of life.

Infants discharged before $48 \mathrm{~h}$ should be screened before discharge; however, this increases the number of false-positive results because of the TSH surge that occurs at birth. A repeat test at 2 to 6 weeks identifies about $10 \%$ of cases.

TSH concentrations $>40 \mathrm{uU} / \mathrm{mL}$ are indicative of congenital hypothyroidism. Borderline TSH levels (20-40 uU/mL) should be repeated. The goal of therapy is to maintain $\mathrm{TSH}<10 \mathrm{uU} / \mathrm{mL}$ [13].

Providing a more accurate easy to collect screening method for proper diagnosis of hypothyroidism is currently extremely important; taking into consideration the peaks at different hours of life, thus decreasing the false results and the need of follow up.

Cord blood TSH is a new screening method where blood for TSH level is taken directly at birth from the umbilical cord. This ensures that the level is taken before the 24-48 hour peak of TSH thus decreasing the false positive results and improves parent compliance.

However, multiple studies showed that the level of cord blood TSH is affected by several perinatal factors thus yielding false positive results.
So, this study will discuss the relationship between cord blood TSH taken at birth and heel prick filter paper TSH that is taken at 24-48 hours of life routinely for neonatal screening, and the influence of perinatal factors on both levels.

\section{Methods}

This cross-sectional study was conducted in the normal newborn nursery at Makassed General Hospital (MGH), a tertiary care center with average of 100 deliveries per month. Study was approved by the institutional review board of the hospital. It included 517 live newborns delivered at MGH between November 2016 and February 2017 and between November 2018 to February 2019. All healthy newborns born with gestational age equal to or above 35 weeks, with good APGAR score (7 or more) and less than 5 days old were included in the study total of 252 live newborns. Exclusion criteria were: Neonates who required ICN admission; and whose mothers were hypothyroid or on any thyroid treatment.

An informed consent was obtained from either of the parents. Antenatal and intra-partum information was noted from mother's medical record. Blood samples were drawn for TSH assay as per unit's protocol, directly at birth, through a $5 \mathrm{~mL}$ syringe from the maternal end of the cord immediately after the cord was cut. The sample collected was kept at room temperature of around $25^{\circ} \mathrm{C}$ and was transported to laboratory within one hour. The sample was analyzed within 3 hours using electrochemiluminescence immunoassay on Cobas e 411 analyser. Another sample of blood was drawn by heel prick on filter paper for radioimmunoassay measurement of $\mathrm{TSH}$ before the neonate discharge at 24-48 hour of life. All neonates who had cord blood TSH values more than $20 \mathrm{uU} / \mathrm{mL}$ or heel prick TSH values more than $15 \mathrm{uU} / \mathrm{mL}$ were advised to repeat TSH assessment within 14 days of life. The results of the two samples where afterwards compared.

\section{DeMOgRaPhics OF THE STUDY}

Characteristics studied for each newborn included gender, birth weight, gestational age, birth order, maternal age, maternal chronic illness, course of pregnancy whether complicated by hypertension or preterm labor, duration of labor in hours, mode of delivery and the indication of $\mathrm{C}$-section delivery (elective, failure to progress, fetal distress).

\section{Results}

517 newborns were born at the normal newborn nursery at (MGH) between November 2016 and February 2017 and November 2018 and February 2019. 
252 newborns were enrolled to participate in the study. $153(59 \%)$ of the newborns were females and $103(40 \%)$ were males. 244 (95\%) had a birth weight appropriate for gestation,247 (96\%) were full term and $8(3 \%)$ were late premature, $86(33 \%)$ were first birth orders ,81 (31\%) were second birth orders, and 89 $(34 \%)$ were of higher birth orders . 221 ( $82 \%)$ of mothers were between 20 and 35 years of age, $9(3.5 \%)$ were below 20 years of age and $36(14 \%)$ were above 35 years of age.

$212(83 \%)$ of pregnancies were of smooth course and 44(17\%) were complicated either by preterm labor $27(10 \%)$, or pregnancy induced hypertension $11(4 \%) .247(96 \%)$ of mothers were previously healthy and $9(3.5 \%)$ had chronic illness.

$174(68.3 \%)$ of the deliveries were by Csection, $80(31 \%)$ were by normal vaginal delivery and $2(0.8 \%)$ were by assisted vaginal delivery. $96(55 \%)$ of C-sections were elective, $48(27.5 \%)$ were due to nonprogress of labor, and $11(6.3 \%)$ were due to fetal distress and $19(11 \%)$ other conditions were cause of Csection. All newborns had a good APGAR score (more or equal to 7) and did not require resuscitation. (Table 1)
The cord blood TSH values ranged between $1.3 \mathrm{microIU} / \mathrm{mL}$ and $17 \mathrm{microIU} / \mathrm{ml}$. The heel prick TSH level taken for the same newborn at 24 hours of life was at upper limit of normal $(15 \mathrm{microIU} / \mathrm{mL})$, repeat test was recommended however refused by the parents.

Cord blood TSH was higher but within normal range with $($ mean=6.8) in comparison to Heel Prick $\mathrm{TSH}$ (mean=5.3) with a statistically significant P-value $(<0.0001)$ (Table-2).

Table-3 studied the Cord blood TSH and Heel prick TSH values in accordance with perinatal factors. Cord blood TSH values were not significantly affected with any of perinatal complication that was examined during this study according to maternal age, mode of delivery, gender, birth order, birth weight, gestational age, pregnancy course, preterm labor, and maternal illness and indication. None of the studied parameters also had a significant effect on heel prick TSH.

Table-4 studied the influence of perinatal factors on Cord-Heel TSH difference which also showed no statistical significance regarding the parameters examined in this study.

Table-1: Baseline Characteristics of Study Population

\begin{tabular}{|c|c|c|}
\hline & & Total $\mathbf{N}=252$ \\
\hline \multirow[t]{2}{*}{ Gender } & Male & $101(40.1 \%)$ \\
\hline & Female & $151(59.9 \%)$ \\
\hline \multirow[t]{3}{*}{ Birth weight } & Small for gestation & $6(2.4 \%)$ \\
\hline & Appropriate for gestation & $241(95.6 \%)$ \\
\hline & Large for gestation & $5(2.0 \%)$ \\
\hline \multirow[t]{3}{*}{ Gestational age } & Full term(37-41weeks) & $243(96.4 \%)$ \\
\hline & Preterm( less than 37 weeks GA) & $8(3.2 \%)$ \\
\hline & Extremely preterm (<32 weeks GA) & $1(0.4 \%)$ \\
\hline \multirow[t]{3}{*}{ Birth order } & First & $82(32.5 \%)$ \\
\hline & Second & $81(32.1 \%)$ \\
\hline & Third or higher & $89(35.3 \%)$ \\
\hline \multirow[t]{3}{*}{ Maternal age } & $<20$ & $6(2.4 \%)$ \\
\hline & $20-35$ & $211(83.7 \%)$ \\
\hline & $>35$ & $35(13.9 \%)$ \\
\hline \multirow[t]{2}{*}{ Pregnancy course } & Smooth & $209(82.9 \%)$ \\
\hline & $\begin{aligned} \text { Complicated } & \\
- & \text { Preterm labor }(\text { Preterm labour }) \\
- & \text { Pregnancy induced hypertension }(\text { Hypertension=3) }\end{aligned}$ & $\begin{array}{l}43(17.1 \%) \\
26(10.3 \%) \\
11(4.4 \%)\end{array}$ \\
\hline \multirow[t]{2}{*}{ Mother chronic illness } & No & $243(96.4 \%)$ \\
\hline & Yes & $9(3.6 \%)$ \\
\hline Duration of labor in hours & Mean $( \pm \mathrm{SD})$ & $4.96(4.63)$ \\
\hline \multirow[t]{3}{*}{ Mode of delivery } & Normal Vaginal delivery & $78(31.0 \%)$ \\
\hline & Caesarian Section & $174(69.0 \%)$ \\
\hline & Assisted vaginal delivery & $2(0.8 \%)$ \\
\hline \multirow[t]{4}{*}{ Indication of C-section } & Elective & $96(55.2 \%)$ \\
\hline & Fetal distress & $11(6.3 \%)$ \\
\hline & Non progress of labor & $48(27.6 \%)$ \\
\hline & Other & $19(10.9 \%)$ \\
\hline
\end{tabular}


Table-2: Comparison between cord blood TSH and Heel Prick filter paper TSH values in newborns

\begin{tabular}{|l|l|l|l|}
\hline \multirow{2}{*}{\begin{tabular}{l} 
TSH value(microU/mL) \\
\multirow{2}{*}{$*$ Frequency $(\%)$}
\end{tabular}} & $\begin{array}{l}\text { TSH-CORD blood } \\
\text { N=252 }\end{array}$ & $\begin{array}{l}\text { TSH-HEEL PRICK } \\
\text { N=252 }\end{array}$ \\
\cline { 2 - 4 } & $15.1-20$ & $4(1.6 \%)$ & $250(99.2 \%)$ \\
\cline { 2 - 4 } & $20.1-30$ & $0(0.0 \%)$ & $2(0.8 \%)$ \\
\hline \multirow{2}{*}{$\begin{array}{l}\text { TSH value(microU/mL) } \\
*\end{array}$} & $\leq 15$ & $6.4(2.5)$ & $0(0.0 \%)$ \\
\cline { 2 - 4 } & $15.1-20$ & $6.6(1.4)$ & $5.1(2.7)$ \\
\cline { 2 - 4 } & $20.1-30$ & - & $19.6(\mathrm{~N} / \mathrm{A})$ \\
\hline P-value (Anova) & & $<0.0001$ & $<0.0001$ \\
\hline $\begin{array}{l}\text { Total average } \\
\text { Mean }( \pm \text { SD) }\end{array}$ & & $6.6(2.8)$ & $5.2(3.0)$ \\
\hline P-value (T test) & & $<0.0001$ & $<0.0001$ \\
\hline
\end{tabular}

Table-3: Comparison of Cord Blood TSH and Heel prick TSH values in Accordance with Perinatal factors

\begin{tabular}{|c|c|c|c|c|c|}
\hline & Mean $( \pm$ SD) & $\begin{array}{l}\text { TSH-CORD } \\
\text { blood } \\
\mathrm{N}=256 \\
\end{array}$ & p-value & $\begin{array}{l}\text { TSH-HEEL } \\
\text { PRICK } \\
\text { N=256 }\end{array}$ & p-value \\
\hline \multirow[t]{2}{*}{ Gender } & Male & $6.35(2.6)$ & \multirow[t]{2}{*}{0.31} & $5.24(2.7)$ & \multirow[t]{2}{*}{0.97} \\
\hline & Female & $6.71(3.0)$ & & $5.22(3.2)$ & \\
\hline \multirow[t]{3}{*}{ Birth weight } & Small for gestation & $6.24(2.4)$ & \multirow[t]{3}{*}{0.95} & $4.73(3.3)$ & \multirow[t]{3}{*}{0.91} \\
\hline & Appropriate for gestation & $6.58(2.8)$ & & $5.24(3.0)$ & \\
\hline & Large for gestation & $6.42(1.57)$ & & $5.10(2.0)$ & \\
\hline \multirow[t]{3}{*}{ Gestational age } & Full term(37-41weeks) & $6.59(2.8)$ & \multirow[t]{3}{*}{0.80} & $5.24(2.9)$ & \multirow[t]{3}{*}{0.59} \\
\hline & Preterm( less than 37 weeks GA) & $5.95(2.9)$ & & $5.23(3.6)$ & \\
\hline & Extremely preterm $(<32$ weeks GA) & $6.00()$. & & $2.20()$. & \\
\hline \multirow[t]{3}{*}{ Birth order } & First & $6.95(3.0)$ & \multirow[t]{3}{*}{0.10} & $5.19(2.8)$ & \multirow[t]{3}{*}{0.48} \\
\hline & Second & $6.72(3.06)$ & & $4.96(2.8)$ & \\
\hline & Third or higher & $6.08(2.2)$ & & $5.50(3.3)$ & \\
\hline \multirow[t]{3}{*}{ Maternal age } & $<20$ & $5.70(5.0)$ & \multirow[t]{3}{*}{0.74} & $4.25(1.7)$ & \multirow[t]{3}{*}{0.55} \\
\hline & $20-35$ & $6.60(2.7)$ & & $5.31(3.1)$ & \\
\hline & $>35$ & $6.55(2.59)$ & & $4.91(2.3)$ & \\
\hline \multirow[t]{2}{*}{ Pregnancy course } & Smooth & $6.47(2.5)$ & \multirow[t]{2}{*}{0.21} & $5.42(3.1)$ & \multirow[t]{2}{*}{0.12} \\
\hline & Complicated & $7.05(3.7)$ & & $4.58(2.6)$ & \\
\hline Preterm labor & $\begin{array}{l}\text { No } \\
\text { Yes }\end{array}$ & $\begin{array}{l}6.59(2.8) \\
6.40(2.6)\end{array}$ & 0.74 & $\begin{array}{l}5.32(3.0) \\
4.42(2.6)\end{array}$ & 0.14 \\
\hline \multirow[t]{2}{*}{ Mother chronic illness } & No & $6.53(2.8)$ & \multirow[t]{2}{*}{0.29} & $5.26(3.0)$ & \multirow[t]{2}{*}{0.40} \\
\hline & Yes & $7.54(2.2)$ & & $4.41(1.7)$ & \\
\hline \multirow[t]{2}{*}{ Mode of delivery } & Normal Vaginal Delivery & $7.04(2.9)$ & \multirow[t]{2}{*}{0.07} & $5.58(2.6)$ & \multirow[t]{2}{*}{0.20} \\
\hline & Caesarian Section & $6.35(2.7)$ & & $5.07(3.1)$ & \\
\hline \multirow[t]{4}{*}{ Indication of C-section } & Elective & $6.59(2.6)$ & \multirow[t]{4}{*}{0.18} & $5.20(3.5)$ & \multirow[t]{4}{*}{0.34} \\
\hline & Fetal distress & $7.21(4.4)$ & & $4.79(2.9)$ & \\
\hline & Non progress of labor & $6.11(2.7)$ & & $5.34(2.6)$ & \\
\hline & Other & $5.32(2.1)$ & & $3.89(1.8)$ & \\
\hline
\end{tabular}


Table-4: Comparison between Cord-Heel TSH difference and Perinatal factors

\begin{tabular}{|c|c|c|c|}
\hline & & Cord-Heel TSH difference & P-value \\
\hline \multirow[t]{2}{*}{ Gender } & Male & $1.11(3.2)$ & \multirow[t]{2}{*}{0.41} \\
\hline & Female & $1.49(3.8)$ & \\
\hline \multirow[t]{3}{*}{ Birth weight } & Small for gestation & $1.51(2.5)$ & \multirow[t]{3}{*}{0.99} \\
\hline & Appropriate for gestation & $1.33(3.6)$ & \\
\hline & Large for gestation & $1.3(3.3)$ & \\
\hline \multirow[t]{3}{*}{ Gestational age } & Full term(37-41weeks) & $1.35(3.6)$ & \multirow[t]{3}{*}{0.70} \\
\hline & Preterm( less than 37 weeks GA) & $0.73(2.3)$ & \\
\hline & Extremely preterm $(<32$ weeks GA) & $3.8()$. & \\
\hline \multirow[t]{3}{*}{ Birth order } & First & $1.76(3.8)$ & \multirow[t]{3}{*}{0.06} \\
\hline & Second & $1.77(3.5)$ & \\
\hline & Third or higher & $0.57(3.3)$ & \\
\hline \multirow[t]{3}{*}{ Maternal age } & $<20$ & $1.45(5.3)$ & \multirow[t]{3}{*}{0.86} \\
\hline & $20-35$ & $1.29(3.5)$ & \\
\hline & $>35$ & $1.64(3.7)$ & \\
\hline \multirow[t]{2}{*}{ Preterm labour } & No & $1.27(3.5)$ & \multirow[t]{2}{*}{0.34} \\
\hline & Yes & $1.97(3.5)$ & \\
\hline \multirow[t]{2}{*}{ Mode of delivery } & Normal Vaginal Delivery & $1.46(3.8)$ & \multirow[t]{2}{*}{0.73} \\
\hline & Caesarian Section & $1.29(1.3)$ & \\
\hline \multirow[t]{4}{*}{ Indication of C-section } & Elective & $1.39(3.6)$ & \multirow[t]{4}{*}{0.50} \\
\hline & Fetal distress & $2.42(3.5)$ & \\
\hline & Non progress of labor & $0.78(2.9)$ & \\
\hline & Other & $1.42(3.5)$ & \\
\hline
\end{tabular}

\section{DISCUSSION}

Congenital hypothyroidism is one of the major and most common preventable causes of mental retardation. Universal screening of all neonates has for long been recognized as the most effective method to prevent the severe developmental and physical morbidities associated with congenital hypothyroidism [14].

At birth, the cord blood TSH tends to be high (up to $20 \mathrm{uU} / \mathrm{mL}$ ) and $\mathrm{T} 4$ and $\mathrm{T} 3$ tend to be low. Within 30-60 minutes after birth there is a surge in the level of TSH $(90-160 \mathrm{uU} / \mathrm{mL})$, followed by a rise in the serum T4 and T3 levels by 24 to 48 hours of birth. The TSH declines to normal range by 72 hours. The levels of T4 and T3 decline by 3 weeks but remain higher during infancy. If a newborn has to be assessed for thyroid function, cord blood should be drawn at the time of birth or alternatively after 72 hours so that the physiological changes in the blood levels of TSH do not cause problems in interpretation [15].

Neonatal screening methods measure thyroid stimulating hormone (TSH) level in either cord blood (CB) sample or that obtained from heel prick (HP) sample at 3-4 days of life. Cord blood TSH estimation has the advantages of being easy to collect, noninvasive, and low rates of follow-up loss as the results would be available before the mother leaves the hospital, enabling repeat sampling if needed at the earliest, which is critical for early institution of treatment if necessary. Various maternal and perinatal factors are known to affect the cord blood TSH levels
[16-24]. This study presents the influence of perinatal factors on values of Cord blood and Heel prick TSH.

In our study, Cord blood TSH was of normal (mean=6.8) in comparison to Heel prick TSH (mean=5.06) with a statistically significant $\mathrm{P}$-value $<0.0001$ but within normal ranges. Furthermore, cord blood TSH was not significantly raised in neonates delivered by assisted vaginal delivery than those with $\mathrm{C}$-section and normal vaginal delivery these finding doesn't correlate with the study done by Amit Gupta et al., "Cord Blood Thyroid Stimulating Hormone Level Interpretation in Light of Perinatal Factors" [21], and Rashmi et al., "Effect of Perinatal Factors on Cord Blood Thyroid Stimulating Hormones Levels" [20] which stated that the cord blood TSH mild be affected with the mode of delivery mainly assisted vaginal delivery . Gender had varying effect on cord blood TSH level significant in a few $[20,23,25,26]$ and insignificant in other [21, 22] studies. Gender had no significant effect on cord blood TSH level in the present study. The cord blood TSH level was significantly higher in the first child than the second child or more, finding similar to an earlier study [21]. Birth weight also shown to have varying effect on cord blood TSH level in study done by Rashmi et al [20], did not have significant effect in the present study. Cord blood TSH levels was found to be inversely proportionate to gestational age in one study [20], however had no effect in this study.

Study done by Sunil Raj et al showed Cord Blood TSH levels increasing with increased maternal 
age (P-value $<0.001)$, however in our study there was no significant effect.

Maternal co-morbidities, birth weight, and gestational age did not have significant effect on cord blood TSH level in the present study, findings correlating with previous studies. None of the studied parameters had a significant effect on Heel Prick TSH.

The postnatal surge in TSH levels, common to all newborns, is considered to be mediated through alpha adrenergic stimulation following the cold stress. In a study on neonatal rats, it was demonstrated that perinatal hypoxia increases the secretion of catecholamine's. Similarly, a surge in catecholamine secretion was seen in human neonates during parturition; and this was more in asphyxiated newborns and in vaginally delivered newborns compared to those born by elective caesarean section. Others observed that with perinatal hypoxia there is an increase in endogenous catecholamine. Perinatal stress factors and mode of delivery have a significant impact on cordblood TSH levels and any rise in cord blood TSH should be seen in the light of these factors. This alpha adrenergic stimulation in turn might be responsible for the observed increase in CB TSH in subjects who had low Apgar scores, required active resuscitation after birth, were born through vaginal delivery or nonelective C-section, and to primi-parous mother [21].

Thus it was recognized that multiple perinatal stress factors affected the result of cord blood $\mathrm{TSH}$, giving it a high value in different studies, this study done on 252 babies showed that cord blood TSH is not affected with any of the above parameters giving and easy, safest, and fastest way with no risk of infection to diagnose congenital hypothyroidism and to start treatment within the first 15 days of birth. On the other hand, the heel prick TSH was not affected by these factors but by the physiologic postnatal peek.

\section{Study Limitations}

Our study was limited by being single centered, and having a small sample size. More studies should be performed in the future with larger sample sizes and multiple centers to determine the most accurate screening method for congenital hypothyroidism.

\section{Conclusion}

In conclusion, congenital hypothyroidism is one of the most common causes of preventable intellectual disability worldwide. Clinical diagnosis at birth is extremely difficult and initiation of treatment at that time is mandatory. Multiple screening programs worldwide are aimed at detecting this condition. These screening programs measure TSH level either directly at birth from cord blood, or at 24-48 hours predischarge from nursery from heel prick. Cord blood
TSH has the advantage of being easy to collect, noninvasive, and has better compliance from the parents with faster results and this study showed that it is not affected by any perinatal stressful condition and mode of delivery which make it the best way for screening for congenital hypothyroidism. On the other hand, heel prick TSH is more invasive, has less compliance for follow up, and overlaps with the physiologic peak that the TSH has postnatal. However, this study proved that it is not affected by any perinatal stressful situation.

Further studies with larger sample sizes should be done to have an international decision on which test is more accurate to use, thus having better patient compliance regarding cost and follow up.

\section{REFERENCES}

1. Klein AH, Meltzer S, Kenny FM. Improved prognosis in congenital hypothyroidism treated before age three months. Journal Pediatr, 1972;81:912.

2. Bernal J. Action of thyroid hormone in brain. Journal Endocrinol Invest. 2002;25(3):26888.

3. Zoeller RT, Rouext J. Timing of thyroid hormone action in the developing brain: clinical observations and experimental findings. Journal Neuroendocrionol. 2004;16(10):804-18.

4. Buyukgebiz A. Congenital hypothyroidism: clinical aspects and late consequences. Pediatr Endoerinol Rev. 2003;1(suppl 2):185-90.

5. Rovet J, Walker W, Bliss B, Buchanan L, Ehrlich R. Long-term sequelae of hearing impairment in congenital hypothyroidism. The Journal of pediatrics. 1996 Jun 1;128(6):776-83.

6. Bellman SC, Davies A, Fuggle PW, Grant DB, Smith I. Mild impairment of neuro-otological function in early treated congenital hypothyroidism. Archives of disease in childhood. 1996 Mar 1;74(3):215-8.

7. Rose SR, Brown RS, American Academy of Pediatrics, American Thyroid Association. Update of newborn screening and therapy for congenital hypothyroidism. Pediatrics. 2006 Jun 1;117(6):2290-303.

8. Foley JT, Klein AH, Agustin AV. Adaptation of TSH filter paper method for regionalized screening for congenital hypothyroidism. The Journal of laboratory and clinical medicine. 1977 Jul;90(1):11-7.

9. Klett M. Epidemiology of congenital hypothyroidism. Experimental and Clinical Endocrinology \& Diabetes. 1997;105(S 04):1923.

10. Rose SR, Brown RS, American Academy of Pediatrics, American Thyroid Association. Update of newborn screening and therapy for congenital hypothyroidism. Pediatrics. 2006 Jun 1;117(6):2290-303. 
11. Karamizadeh Z, Saneifard H, Amirhakimi G, Karamifar H, Alavi M. Evaluation of congenital hypothyroidism in Fars province, Iran. Iranian journal of pediatrics. 2012 Mar;22(1):107-112.

12. Smith L. Updated AAP guidelines on newborn screening and therapy for congenital hypothyroidism. Am $\quad$ Fam Physician. 2007 Aug 1;76(3):439-444.

13. Thyroid Disorders, Lange Neonatology 2004, 79:777-780

14. Manglik AK, Chatterjee N, Ghosh G. Umbilical cord blood TSH levels in term neonates: a screening tool for congenital hypothyroidism. Indian Pediatr. 2005 Oct 1;42(10):1029-32.

15. Meena P, Desai VB. Pediatric Endocrine Disorders, Orient Longman LtD, 2001;184.

16. . Manglik AK, Chatterjee N, Ghosh G. Umbilical cord blood TSH levels in term neonates: A screening tool for congenital hypothyroidism. Indian Pediatr. 2005;42:102932.

17. Meghana KP, Kamble BD, Suryawanshi PB, Melinkeri RR. Umbilical cord TSH levels in term small for gestational age neonates. Indian Journal Res. 2013;2:294-5.

18. Sangeeta N, Kamala L, Karki P, Basar G, Kumar YI, Singh LR. Assessment of umbilical cord TSH in term neonates in Manipur. IOSR J Dent Med Sci. 2013;9:14-7.

19. Nayak CD, Kamath M, Nayak DM, Nagesha KM. Status of pituitary-thyroid axis of newborns and its relationship with anthropometry and maternal factors at birth. International Journal of Pharma and Bio Sciences. 2012 Oct 1;3(4):51-7.

20. Seth A, Sekhri T, Agarwal A. Effect of perinatal factors on cord blood thyroid stimulating hormone levels. Journal of Pediatric Endocrinology and Metabolism. 2007;20(1):59-64.

21. Gupta A, Srivastava S, Bhatnagar A. Cord blood thyroid stimulating hormone level-interpretation in light of perinatal factors. Indian pediatrics. 2014 Jan 1;51(1):32-6.

22. Raj S, Baburaj S, George J, Abraham B, Singh S. Cord blood TSH level variations in newbornExperience from a rural centre in Southern India. Journal of clinical and diagnostic research: JCDR. 2014 Jul;8(7):PC18-20.

23. Chan LY, Leung TN, Lau TK. Influences of perinatal factors on cord blood thyroid-stimulating hormone level. Acta obstetricia et gynecologica Scandinavica. 2001 Jan 1;80(11):1014-8.

24. Miyamoto N, Tsuji M, Imataki T, Nagamachi N, Hirose S, Hamada Y. Influence of Mode of Delivery on Fetal Pituitary-Thyroid Axis. Pediatrics International. 1991 Jun;33(3):363-8.

25. Kim EY, Park SK, Song CH, Lim SC. Perinatal factors affecting thyroid stimulating hormone (TSH) and thyroid hormone levels in cord blood. Korean Journal of Pediatrics. 2005 Feb $1 ; 48(2): 143-7$.

26. Chan LY, Fok WY, Sahota D, Lau TK. Cord blood thyroid-stimulating hormone level and risk of acidosis at birth. European Journal of Obstetrics \& Gynecology and Reproductive Biology. 2006 Feb 1;124(2):173-177. 